\title{
Implementation \& Analysis of Integrated Utility System in Developing Nation like India
}

\author{
http://dx.doi.org/10.3991/ijes.v4i2.5757 \\ Rajan Gupta ${ }^{1}$, Sunil K. Muttoo ${ }^{1}$ and Saibal K. Pal ${ }^{2}$ \\ ${ }^{1}$ University of Delhi, Delhi, India \\ ${ }^{2}$ SAG Lab, Defense Research \& Development Organization, Delhi, India
}

\begin{abstract}
Public utility systems are prevalent around the world but are struggling in developing nations like India to work efficiently. Integration of different utilities can be a possible solution on the technology front, so that more requests can be handled with lesser problems. This study provides the implementation design and benefits of an already proposed integration system by the same authors. It is found that Data Storage, Access Time, Transaction Cost, security cost and server's busy time can become more effective if the implementation of integration system can be put in place. The working prototype is based on three utilities (Gas, Power \& Water) of Delhi-NCR, India.
\end{abstract}

Index Terms-Utility System, India, Developing Nation

\section{INTRODUCTION}

Public utility sector comprise of general utility services being used by the citizens of a country in daily routine. It comprise of power, gas, water, sanitation, telephone, etc. Although the rise in demand for such services has been comparatively stable in last few years in developed countries, the demand has risen sharply in developing countries like India and China [1-7].

The utility sector has been governed by strict regulations over the past few years but open and liberalized markets have been the major forces behind the improvement in this area. Companies have time and again experimented with demand side management, environment regulatory, and technological innovation. And one such example of efficiency followed by various utilities in different countries in the integrated system. Through this system, the public side management is done through single window for majority of the utilities saving time and energy for various customers. DEWA [8] or Dubai electricity and water authority is one such example of integration along with Gas and electric utility in San Diego USA [9] and Baltimore.

India is bound to contribute heavily to utility system around the world and its demand will rise to the comparable state as that to China by 2035 [10]. Therefore, there is a need to drive efficiency in the process of Indian Utility Systems too. Within India and specifically in its capital city, the utility system exists independently. Either they are fully governed by the government or are under the model public-private partnership (PPP). Since the processing system is under the same governing body i.e. Government of National Capital Region, there is a welldefined possibility of the integration of the various utilities. The major utilities that can be combined are power, gas and electricity [11].
The purpose of this study is to present the implementation details of the proposed integrated system which is known as Integrated System Application for Utilities (ISAU). The designed architecture, security concerns, its basic data flow and process, data headers, services merged and efficiency of the ISAU is discussed in various sections, respectively.

\section{Proposed SCHEME}

The integrate system was proposed earlier by the same authors [12] of this study for which the implementation details are presented in this paper. As per the overview of the system design shown in Figure 1, there are multiple points of contact for the customers to deal with various utility systems. They can be combined through technology access and a common request processing system can be generated. Through this common system, the customer request can be segregated under various utilities and accordingly the processing can be done in order to fulfill the requests.

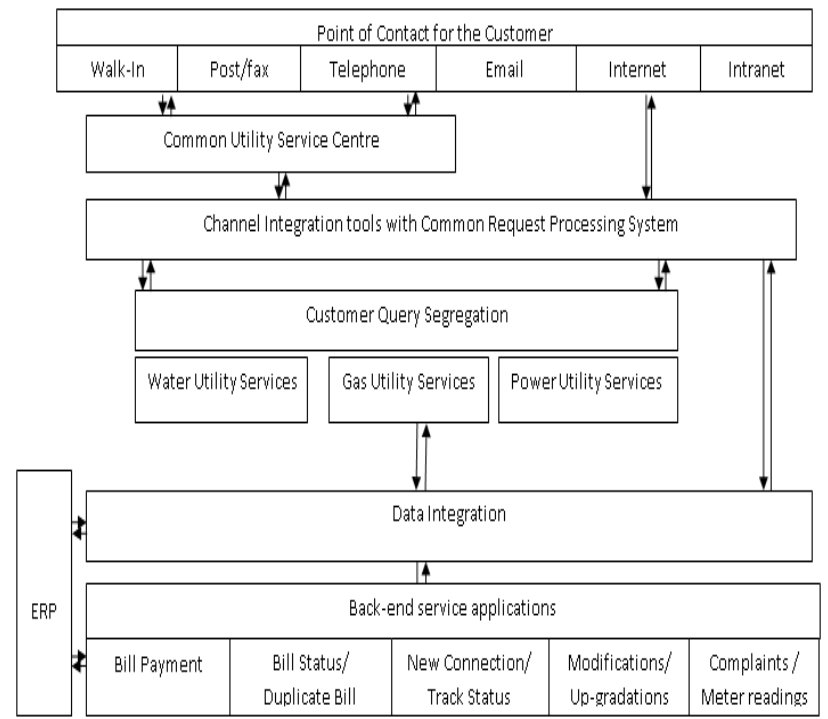

Figure 1. Architecture of ISAU

Their proposed security was also discussed by the same authors [13] in a study through which the architecture was defended for the security of the whole system. Its implementation details are discussed in next section.

\section{IMPLEMENTATION DETAILS}

The system was developed using PHP and MYSQL technology. Before implementing the solution, the 
designing was done using Data Flow Diagrams and Entity Relationships Diagram discussed as follows.

\section{A. Existing System}

The existing system consists of three separate entities viz., Power [14], Gas [15] and Water [16] utility systems. Services offered by all three of them and data stored by them are having similar as well as different fields. However each system can be integrated with each other due to redundancy of data for the same person using all three utility services which is a high percentage in this region.

The various services offered by the Power Utility System are Online bill payment, Complaint management system, New connection request, Change connection request, View the connection details and Archive the bill/ unit consumption history. Any user can register on the online system using CA number, Meter number, Sanction Load, Email Address and a verification code. Every bill generated from the system has attributes like Customer Information, Area Information, Electricity Consumption, Bill Details, and Meter Details.

Similarly, the Water Utility System offered services like knowing the customer information, viewing and printing the latest bill, viewing and printing the balance and last receipt, bill payment options, application for new connection, application for mutation, tracking of the application status, downloading various utility related documents, and Grievance management. The registration process for a customer included a unique number from his offline registration, mobile number, and an email address. The water utility bill had attributes like Customer information, Area information, Water consumption, Bill details, and Meter details.

And the third utility system i.e. Gas utility offered services like Viewing and editing the customer details, viewing the bills, online payment options, archiving history of payment and bills, Complaint management system, and request for new connection. The registration process of online system includes details like Business partner number, mobile number and Email ID. The bill had attributes like customer information, units of gas consumed; bill details w.r.t. slabs, arrears etc., and the meter details.

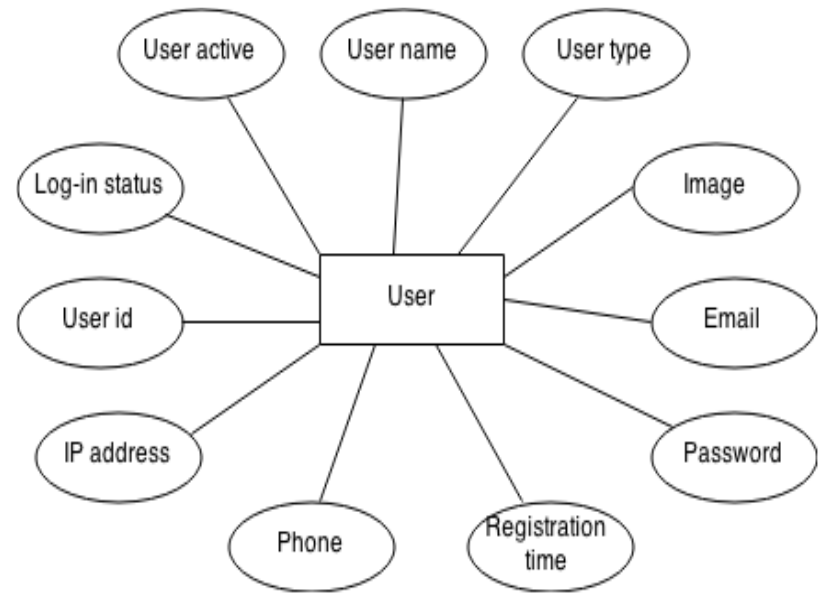

Figure 2. The User Entity and various related attributes

Now all the three individual systems is storing similar information and common information can be stored only once instead of storing it thrice with some additional overheads. New system discusses the Data flow and Entity relationships for the various points in the system.

\section{B. Proposed System: Entity Relationship Diagrams}

The various entities along with their attributes and the relationship between these entities for the proposed system are discussed in this subsection.

The user entity shows it's various attributes like Phone No., Email Id or User Id, Password, IP Address etc. For the same user across all three utilities, all this information will have to be stored just once.

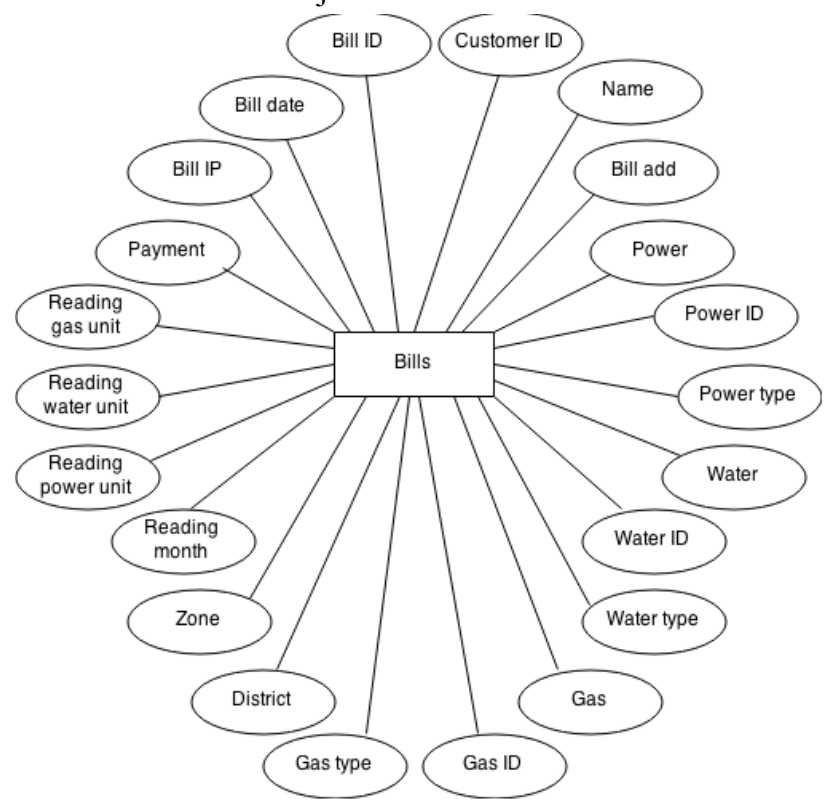

Figure 3. Bill attributes for new system

Just like user entity, the entity of bill also has various attributes like Bill id, customer id, name, power id/type, water id/ type, gas id / type, payment mode, bill IP, bill date. Single bill with null values of non-connection of a utility can be there but a consolidated bill for people with all three connections can prove to be beneficial.

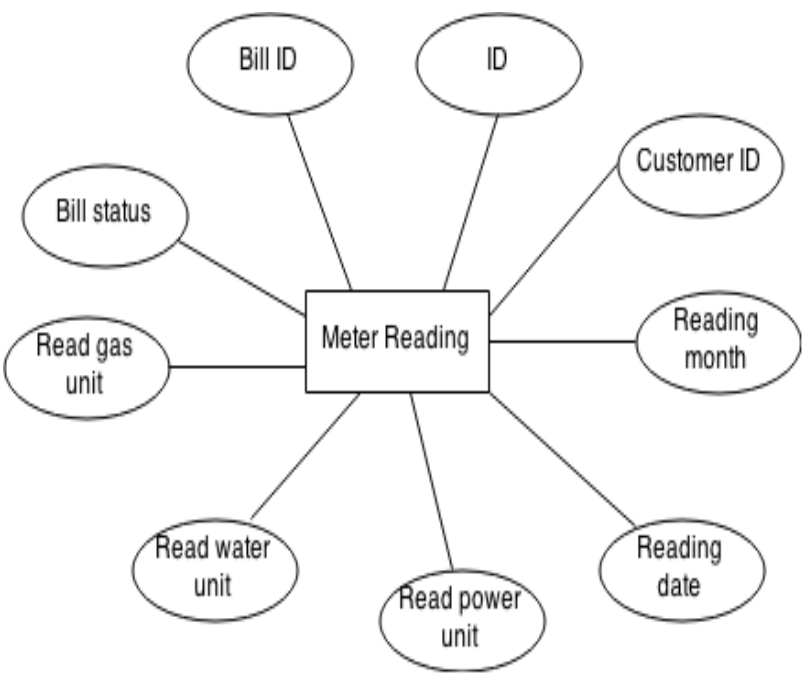

Figure 4. Meter reading attributes for new system

In case of Meter reading, various attributes are meter's unique ID, Customer ID, Reading Month, Reading Date, Read Power Unit, Read Water Unit, Read Gas Unit, Bill 
Id, Bill Status, etc. This will help in collating the meter reading information for all the three types of utilities and single point reading of information can be collected.

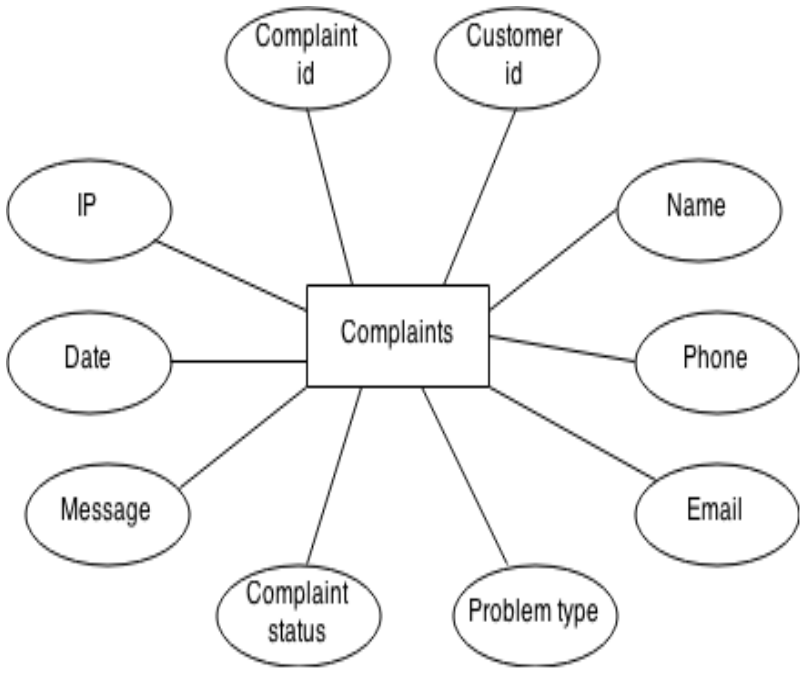

Figure 5. Attributes of Complaint Entity

In the complaint system, the complaint's attributes are complaint id, customer id, name, phone no., email, problem type, complaint status, message, date, IP address, etc. The complaints can be related to any single entity related to meter or billing. Or it can be for common aspects like changing the customer information or the billing area information.

The four entities discussed above forms the core for the proposed system and their attributes makes the design for the database system used for information storage, access and retrieval. The relationships between these entities are shown in following sequence.

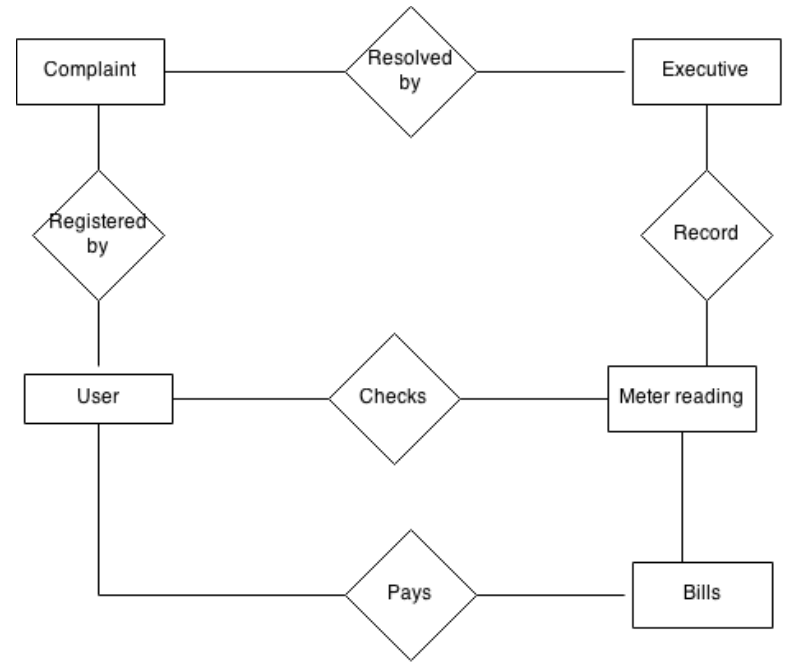

Figure 6. Entity relationship at broad level

As per the Figure 6, the Relationship between each entity is shown. A User can register a Complaint and Complaint can be registered by the User only. Bills which are generated through meter readings are also paid by the user. Users can also check the Meter Reading, while the executive records the meter reading into the system whenever required. In the same way, Executive resolves the Complaint or Complaint resolved by the Executive. So the major tasks amongst the various entities are registration, bill viewing \& paying, checking and recording of meter and the query resolution. The details of the attributes and their related entities and relations are shown as follows. The executive has almost similar attributes as that of a user but without connection details.

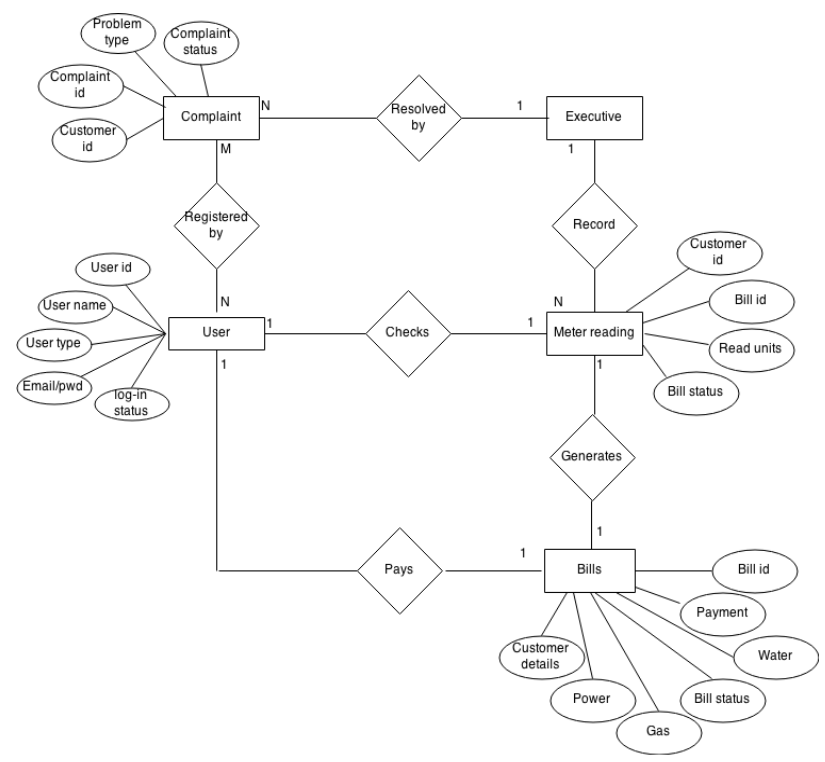

Figure 7. Entity Relationship Diagram in detail for the proposed system

The ERD system in Figure 7 specifies the involvement of every entity with each other. For complaint management system, a complaint can be resolved by only one executive who is responsible for specific task but this executive can resolve multiple queries. Also the same complaint can be raised by multiple users and a single user can raise multiple complaints. With respect to billing, the new system proposes to generate single bill against particular meter reading however, all three utilities will have single consolidated bill only. Also a bill can be paid by single user as it is unique and single user can pay single bill only. Multiple locations of same user has to have some attributes different to generate a different user ID. With respect to meter reading, only one user can check his/ her meter reading and vice versa. However an executive can record multiple meter readings for various user IDs.

\section{Proposed System Flow of Data (DFD)}

After defining the entities, their attributes and relationships for the database designing, it is important to design the flow of events on front end.

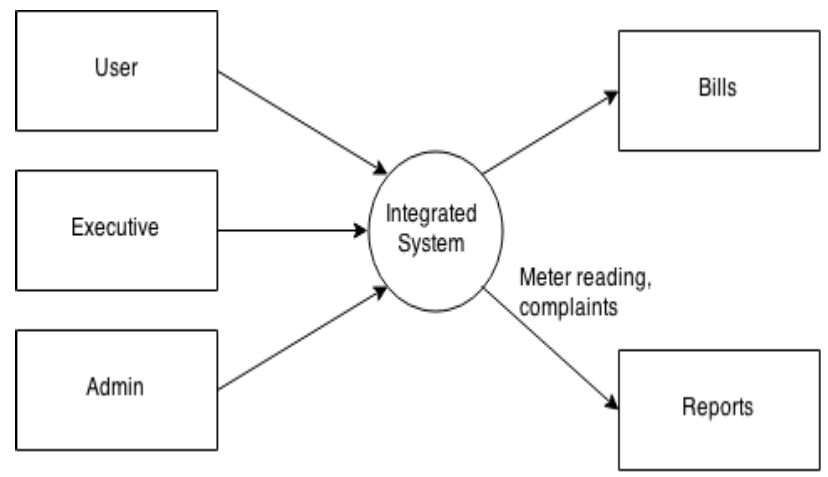

Figure 8. Level Zero DFD for the system 
User/ Executive/ Admin give the input or storage command to the integrated system, which returns the data in form of bills and reports as an output. This is the main function of the proposed integrated system. It can be then divided into various parts.

Part I. At the User End
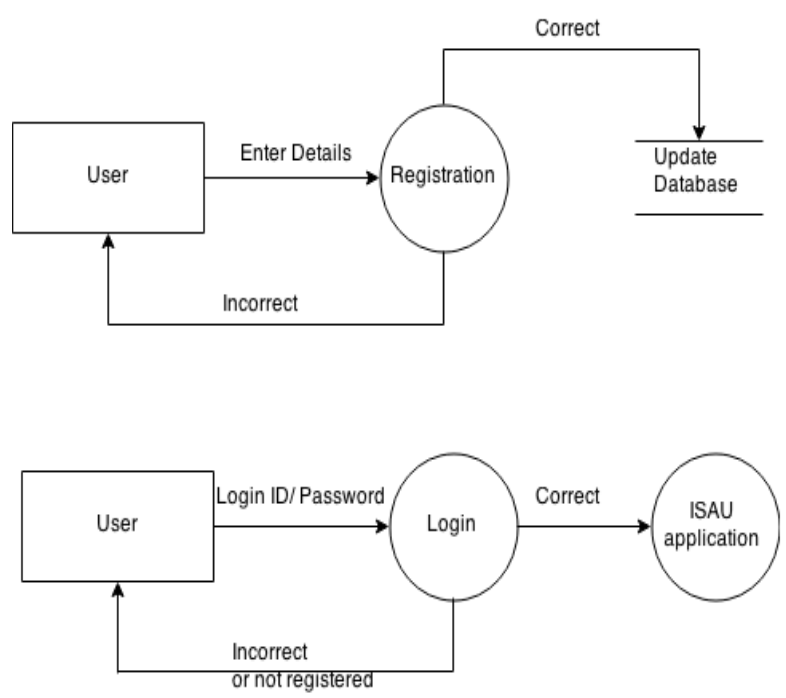

Figure 9. Level 1 DFD for user

This process represents the Registration by the User. Here the User enters the details to the Registration Form and if the details are correct the Database will update otherwise it show the message with incorrect details to the user. Then with the registered details, the user can log into the system and use the integrated system application for utilities. After entering into the system, the user can perform various tasks as shown in Figure 10.

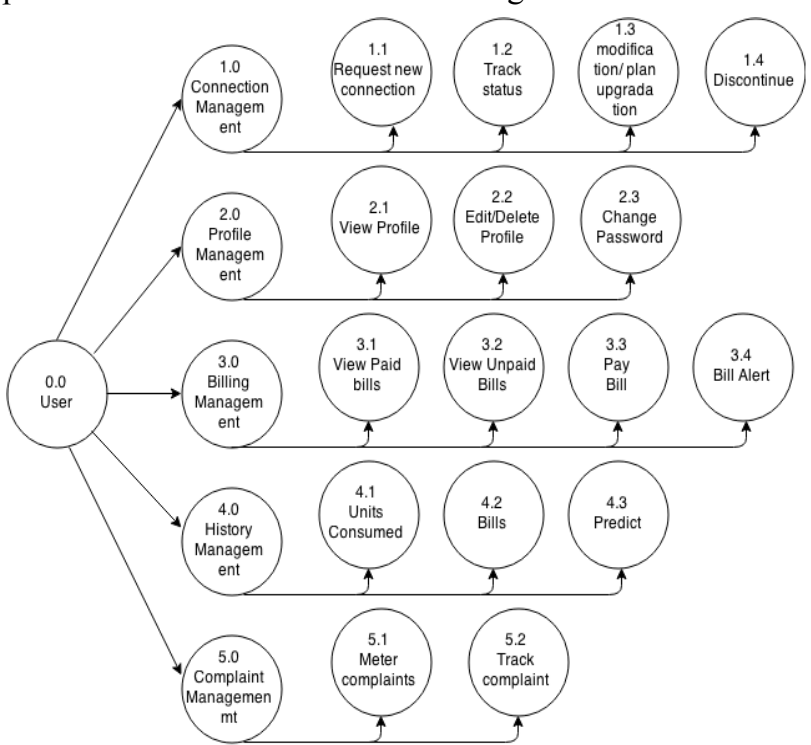

Figure 10. Level 2 DFD for the user logged into the system

This is the main frame of the ISAU (Frontend) which describe various functions of the User like New Connection Management System, Profile Management System, Billing Management System, History Management System, and Complaint Management System. All these function have their own sub functions which are explain as follows.
Phase 1

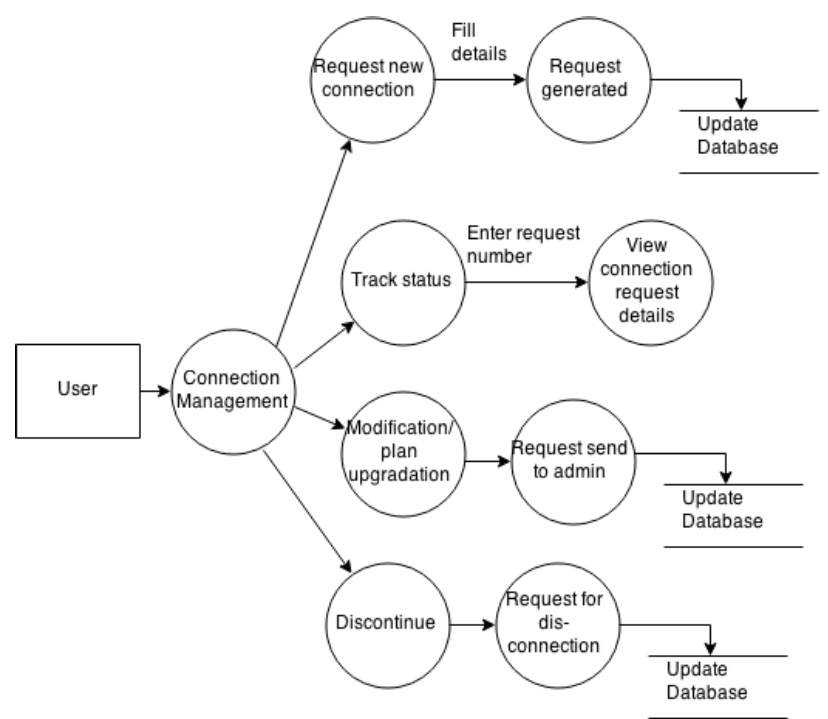

Figure 11. Connection Management System for the Integrated Application

According to First level of ISAU Framework, User has a connection request option for Power, Water or Gas facilities. When User enters the New Connection Management System, he meets with four functionsRequest New Connection, Track Status, Modification/ Plan Up-gradation, Discontinue. If the User request for New Connection, firstly he has to fill the personal details and then the request generates which will update the database. If the User chooses the track status function, then the user has to enter the request number after which the user views connection request details. But if the user chooses Modification/ Plan Up-gradation function, the user has to send a request to the admin with edited details then the database will update. If the user chooses the function of Discontinue, the user has to grant a request for disconnection to the admin, which is processed and then the database is updated.

Phase 2

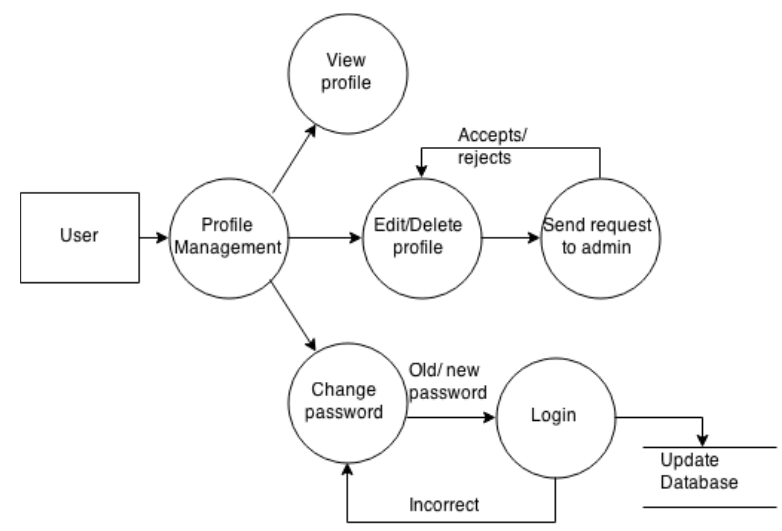

Figure 12. Profile Management for a user in Integrated System

In the second phase of ISAU framework, the User can enter into the Profile Management System where the User can View the profile, Edit or Delete the profile and Change the password of his ID. If the User chooses the Edit/ Delete Profile function then the user has to send the request to the Admin with his ID details and then Confirmation Message (Accepts/ Reject) will be generated 
by the Admin. But if the User chooses the function of Change Password then the User has to enter his Old and New Password with his ID details to the Login ID, if the information is correct then the Database will update otherwise it generate the "Incorrect" message.

\section{Phase 3}

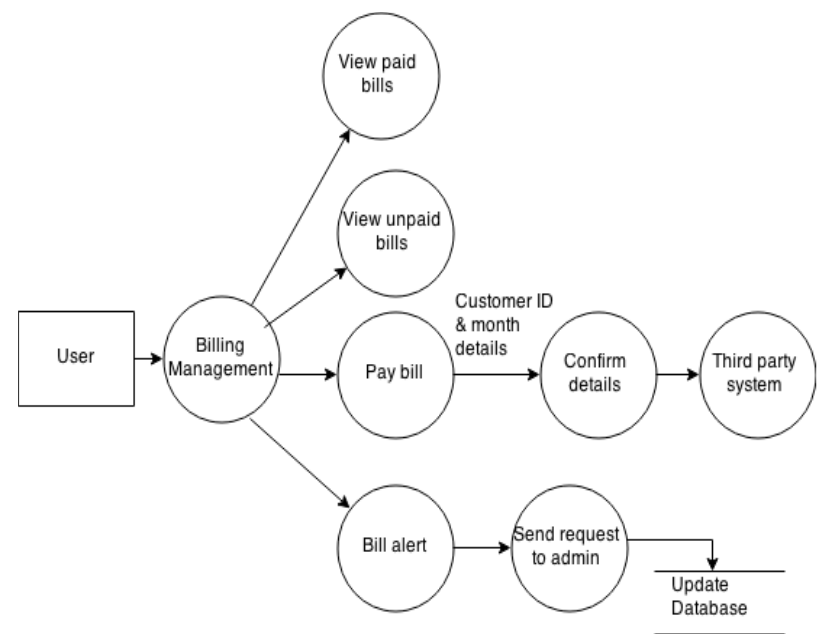

Figure 13. Billing Management System for the ISAU

In the third phase or the Billing Management Process, various activities performed by the user related to billing are illustrated. By this process User enter into billing management system where he can check the multiple functions like Bill Alerts, Pay Bill, View Unpaid Bills, and View Paid Bills. If the User chooses the function of Pay Bill then User has to confirm his details with Customer ID and Month Details to enter into Third Party System for online payment. But if the User chooses the function of Bill Alert then he has to send the request to the Admin and then the information will be fetched from the database and the bill will be generated and stored in the database for the customer to view it.

\section{Phase 4}

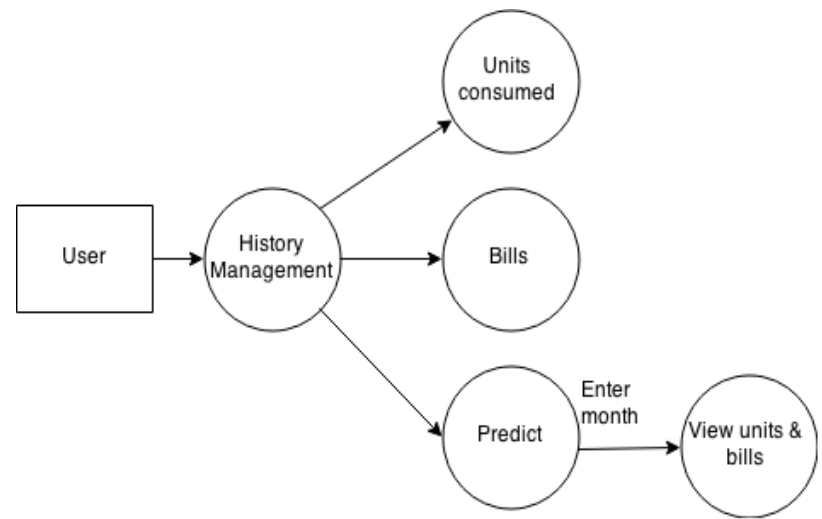

Figure 14. History Management for a user in Integrated System

In the process of fourth phase i.e. History Management System, the user can go to the system and check various functions like Units Consumed, Bills and Predictions for next bills based on his units consumption in the past. If the User chooses to the Predict function, the User has to enter the month for which it wants to predict and can then view the tentative Units and Bills of the month based on his past consumption. This prediction is valid only for users having at least 5 years of monthly data.
Phase 5

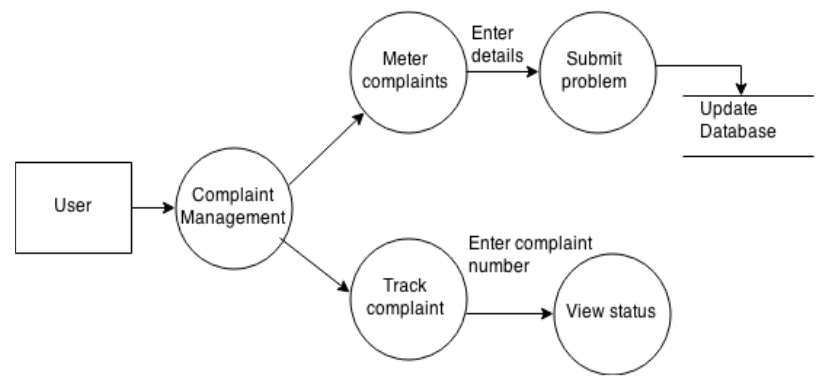

Figure 15. Complaint Management System for the user in ISAU

Now within the fifth phase i.e. Complaint Management process, the role of the User in the Complaint Management System is highlighted. Here, the User enters into Complaint Management system and meets with two main functions like Meter Complaints and Track Complaint. If the User chooses the Meter Complaints then he has to enter his personal details and submit the problem and then the problem will update into the Database. But if the User chooses the Track Complaint then he has to enter the Complaint No. and See the status of the complaint.

\section{Part II. At the Executive/ Admin End}

The above part 1 explained the user processes within the ISAU however executive or admin has different set of functionality within the system. They are discussed as follows.

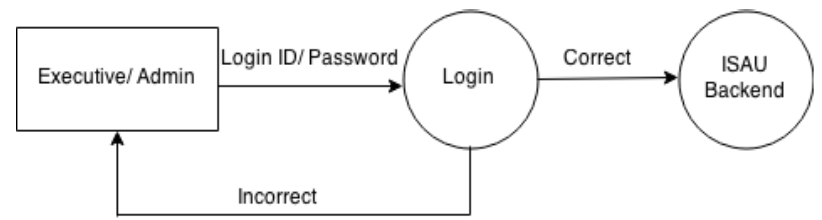

Figure 16. Level 1 DFD for Executive within ISAU

When Admin login to Customer Service Login web page he has to enter the login id and password. If the login id and password is correct then admin come to ISAU backend otherwise Admin goes back to the customer service login web page.

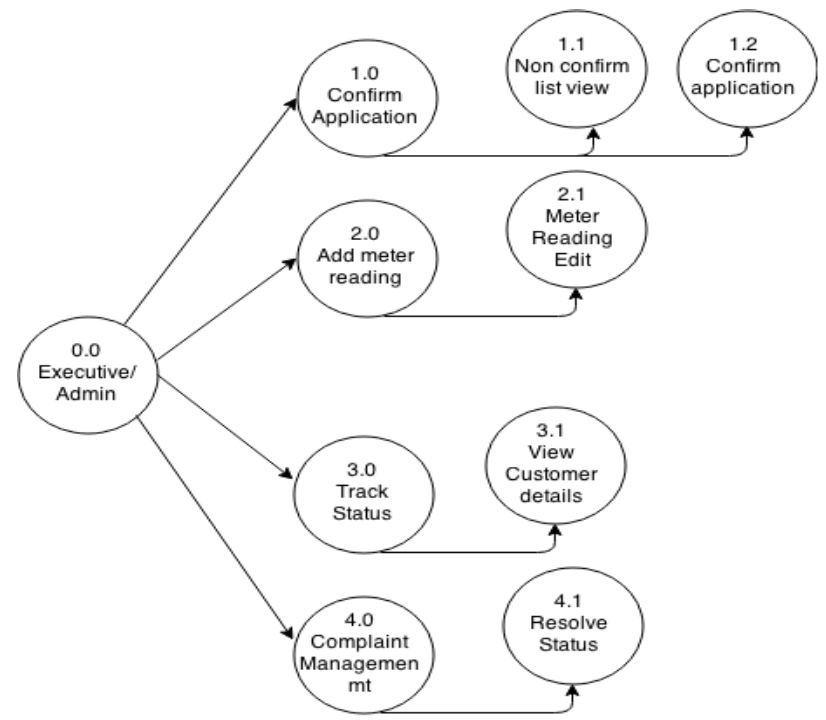

Figure 17. Level 2 DFD for Executive in the ISAU 
When Executive/ Admin enter into ISAU (Backend) framework, then they work on four functionalities which are Confirm Application, Add Meter Reading, Track Status, and Compliant Managements System. All these functions have their own sub functions, which help the Executive / Admin to perform more tasks.

In the ISAU (Backend) framework, user can choose any function from confirm application; add meter reading, track status, complaint management. In the first phase, admin/executive goes to confirm application system then he has two options. First, Non -confirm list which just show the pending request of power, water, and gas connections. But if admin/ executive go to second one then he has to choose the confirm application list, in this admin has to enter the customer ID, if its correct then the power, water or gas services are confirmed but if customer ID is wrong then "Incorrect" message will be generated.

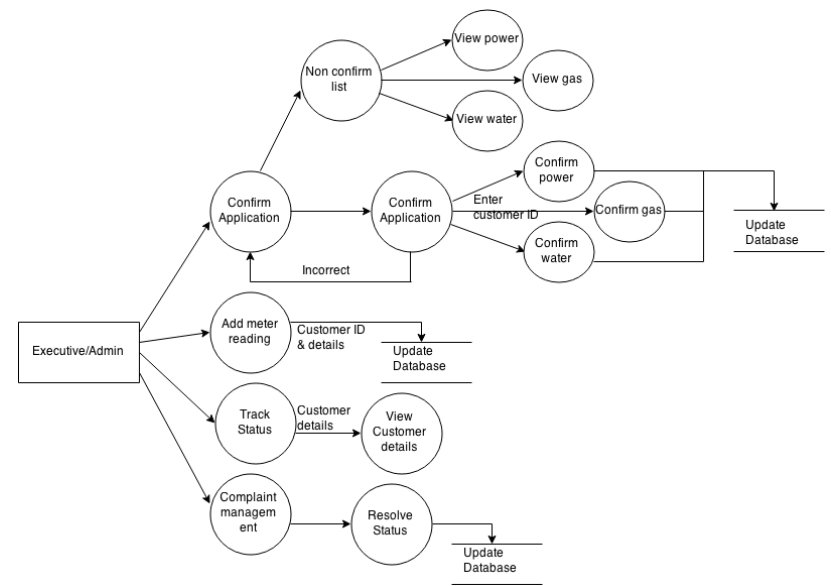

Figure 18. Detailed view of DFD for Executive in ISAU

In the second phase i.e. add meter reading, admin/executive enter the customer ID and its detail to the system and updates the database with this information. In third phase of framework which Track status level, admin/ executive enter the customer ID and view the customer details for billing, connection requests or any other pending grievance. Last phase is that of complaints where Admin/ executive go to the complaint management system and resolve the complaint and update the database status.

\section{IMPLEMENTATION SOLUTION SCREENSHOTS}

The solution has been implemented keeping in mind the various existing features and their integration. The snapshot of home page and login page are as follows.

After registration and successfully logging into the system the following options as shown in Figure 20 emerges for the user. Their functionality is already discussed in the Data Flow Diagrams.

\section{BENEFITS}

There are several benefits that are derived out of this implemented system. The implementation was tested on the actual bills of 1000 customers in Delhi region enrolled with all three utilities. The comparison of individual systems and integrated system is shown in Table 1. There was a considerable amount of savings possible through the integrated system with respect to data storage, access time, payment cost, Security cost and Server busy time.

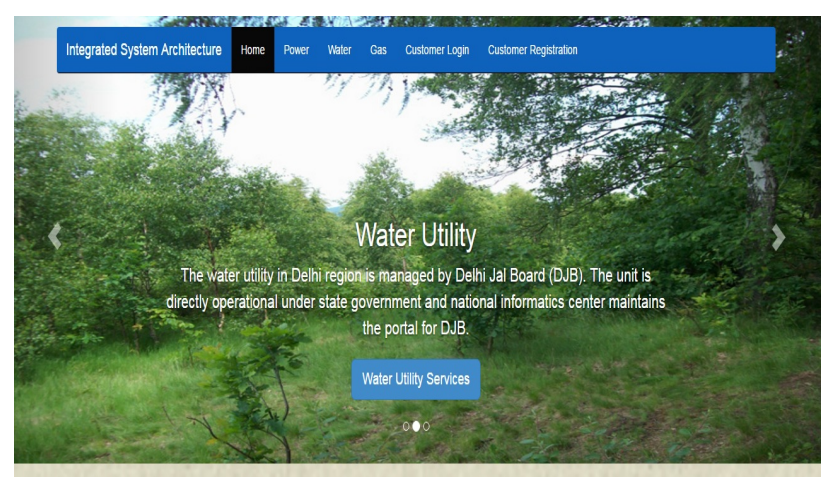

Figure 19. Snapshot of Homepage of the ISAU

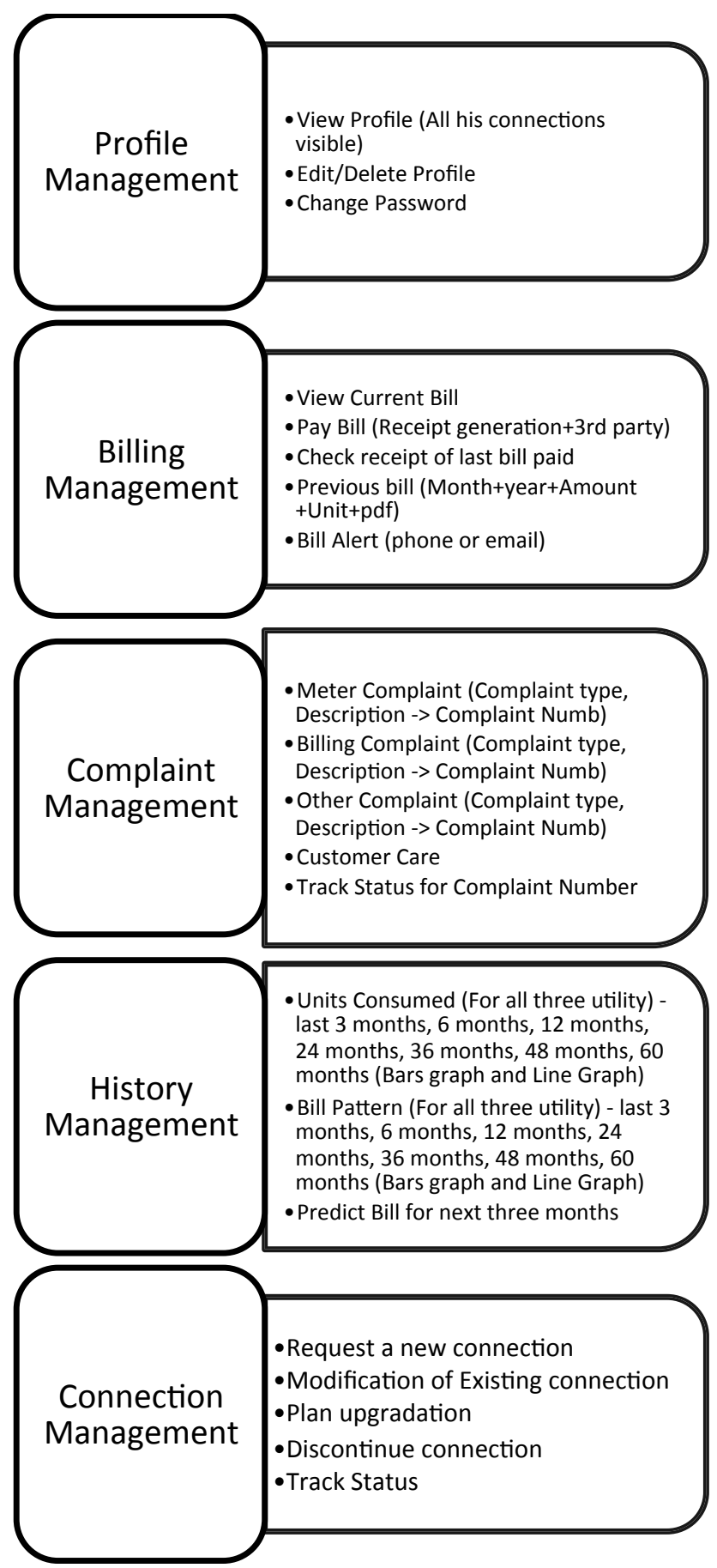

Figure 20. Various options for the user entering into ISAU 
TABLE I.

BENEFITS OF THE ISAU AS COMPARED TO INDIVIDUAL SYSTEMS FOR VARIOUS PARAMETERS

\begin{tabular}{|c|c|c|c|c|c|c|}
\hline & Gas & Water & Power & Total & ISAU & Savings \\
\hline P1 & 30 & 30 & 30 & 90 & 40 & $55 \%$ \\
\hline P2 & 50 & 50 & 50 & 150 & 100 & $33 \%$ \\
\hline P3 & 15 & 10 & 10 & 35 & 15 & $55 \%$ \\
\hline P4 & 25 & 25 & 25 & 75 & 50 & $33 \%$ \\
\hline P5 & 10 & 15 & 10 & 35 & 30 & $15 \%$ \\
\hline
\end{tabular}

Where P1 is Average Per Customer Data Storage (Bytes), P2 is Average Per Customer Access Time (Seconds), P3 is Average Per Customer payment cost for every transaction (INR), P4 is Average Security Cost of Database for every user (INR), and P5 is the Average Busy Time for the server for every user (milliseconds).

Apart from the technology and process efficiency, the overall systems prediction rates were also improved with the integration of the systems through usage of various data analytics techniques. The prediction of defaulters is possible and an experiment to find out defaulter was carried out on the dataset of 1000 users. Defaulters in this particular case were defined as people not paying their bills on time (paying after due date). Parameters like residence area, total amount, units consumed and bill month were found significant to predict the date of billing. Cross department billing predictions were also carried out using regression and predictability of $45 \%$ was achieved. But with more rigorous data, and better availability of the integration details, analytics can become a powerful tool to manage the losses for these utilities. Also better security standards can be applied as per the principals of Information Systems security [17] leading to specific security schemes [18] implementation.

\section{CONCLUSION}

The implementation of the proposed integrated utility system certainly produced beneficial outcomes. The system was implemented using PHP-MySQL but other technology can be used based on the technology used by current systems on individual basis. The integrated system will certainly be helpful for countries like India where the population is rising and thus efficiency in the technological solutions has to be devised in order to lower down the cost and time. It can be replicated by other countries too which are working on the similar individual models of utilities. In future, more analytical datasets can be generated to produce a stronger case of relevant data generated through integrated system. More utilities can be added in the architecture and better eco-system can be developed.

\section{REFERENCES}

[1] Emerging Market Insights, Utilities Sector India, 2013, Report by Emerging Market Information Services

[2] Orient Blackswan, Evolving Perspectives in the Development of Indian Infrastructure, Orient Black Swan Volume 1, 2012
[3] Ernst \& Young, Power transactions and trends, Global power and utilities mergers and acquisitions, 2013

[4] Crisil, CRISIL Infrastructure Advisory High-Level Panel, Study of Various Power Distribution Models in India, 2011

[5] Deloitte, Deloitte Power Solutions Empowering Utilities, Energy Department: REPUBLIC OF SOUTH AFRICA, 2011

[6] PWC, Emerging opportunities and challenges, Power sector Price Waterhouse Coopers, 2012

[7] Black \& Veatch, A Black \& Veatch Report Building a World of Difference. Strategic directions in the U.S. electric utility industry, 2012

[8] SDGE, Official website of San Diego Gas and Electric Utility, Accessed on February 23rd, 2016 from https://www.sdge.com/

[9] DEWA, Official website of Dubai Electric and Water Authority, Accessed on March 30th, 2016 from https://www.dewa.gov.ae/default.aspx

[10] R.M. Koizumi \& F. Onisor, Industry Analysis: Utilities, SUSTAINALYTICS, Feb 2014, Accessed on $15^{\text {th }}$ March 2016 from

http://www.sustainalytics.com/sites/default/files/utilities_february 2014.pdf

[11] M. Burkmier \& T. Hulsebosch, A Platform Approach to Unifying Gas, Water and Electricity Management Systems at Public Utilities, Electric Energy online, Spetember 2011, Accessed on February 28th, 2016 from http://www.electricenergyonline.com/show_article.php?mag=\&art icle $=595$

[12] R. Gupta, S.K.Muttoo, S.K. Pal. Proposal for integrated system architecture in utilities. In Advances in Computing, Communications and Informatics (ICACCI, 2014 International Conference on 2014 Sep 24 (pp. 1995-1998). IEEE. http://dx.doi.org/10.1109/icacci.2014.6968652

[13] S.K.Muttoo, R. Gupta, S.K. Pal. Analyzing Security Checkpoints for an integrated Utility based Information System. In Emerging Research in Computing, Information, Communication and Applications (ERCICA, 2015 International Conference on 2015 August, Vol 3, No 1, chapter 53). Springer Singapore.

[14] TPDL, Accessed from www.ndpl.com on March $3^{\text {rd }}, 2016$

[15] IGL, Accessed from www.iglonline.net on March $5^{\text {th }}, 2016$

[16] DJB, Accessed from www.delhijalboard.nic.in on March $3^{\text {rd }}, 2016$

[17] N. Godbole, Information Systems Security, Wiley Publication

[18] R. Gupta, A Aggarwal, S.K. Pal. "Design and Analysis of New Shuffle Encryption Schemes for Multimedia." Defence Science Journal 62.3 (2012): 159-166. http://dx.doi.org/10.14429/dsj.62. 1008

\section{AUTHORS}

Rajan Gupta is Research Fellow with the Department of Computer Science, Faculty of Mathematical Sciences, University of Delhi, Delhi 110007, INDIA (e-mail: rgupta@cs.du.ac.in).

Sunil K. Muttoo is Head and Associate Professor with the Department of Computer Science, Faculty of Mathematical Sciences, University of Delhi, Delhi 110007, INDIA (e-mail: skmuttoo@cs.du.ac.in).

Saibal K. Pal is Scientist-G with the SAG Lab, Defense Research \& Development Organization, Delhi 110054, INDIA (e-mail: skptech@yahoo.com).

Submitted, 09 April 2016. Published as resubmitted by the authors on 10 May 2016. 